\title{
Software Tools for Project Management - Focus on Collaborative Management
}

\author{
Maria Ester Ferreira and Anabela Pereira Tereso \\ CGIT Research Centre, \\ School of Engineering, University of Minho, \\ 4800-058 Guimarães, Portugal \\ ferreira.ester01@gmail.com, anabelat@dps.uminho.pt
}

\begin{abstract}
Today, projects involve members from different geographical areas more than any other time in history. Thus, adequate Collaborative Project Management Software (CollabPMS) solutions are needed to enable individuals and organizations to manage, communicate and work together across time and space barriers. This article describes a set of managerial and collaborative functionalities that a CollabPMS should provide to support the complexities of a distributed project effectively. Out of hundreds software packages available in the market, four were selected, ProjectLibre, Redmine, Microsoft Project 2013 and Clarizen, to assess if they have the described functionalities. Clarizen can be considered the best software for managing distributed projects, because it provides, by default, all the managerial functions and the collaborative features that support the coordinated collaboration level. ProjectLibre was the software that less stood out in this evaluation, although it provides the majority of the outlined managerial functionalities it doesn't support any level of collaboration.
\end{abstract}

Keywords: Project Management, Distributed Projects, Collaboration, Software.

\section{$1 \quad$ Introduction}

The Project Management Institute, a worldwide leading non-profit professional association in the area of project management, has defined project management as the application of knowledge, skills, tools and techniques to plan activities in order to meet the project's requirements [1]. In the past of project management, projects were typically developed at a single location [2]. However, due to business globalization and technology advancements, a new type of projects called distributed projects have arisen involving project collaborators from different geographical locations and organizations. As the number of distributed projects increases and the project management shifts towards a more collaborative approach, the project management software designed to support the projects at a single location is becoming inadequate [3]. To handle projects involving geographically dispersed teams the project managers should rely on collaborative project management software. This kind of software can help people to manage projects and collaborate more easily regardless of their 
location. In this paper we propose a set of functionalities that a collaborative project management software should have to effectively address the challenges of distributed projects. Currently, the market is loaded with hundreds of project management software solutions to assist in project management. By selecting four software packages available in the market was possible to judge their capability to handle distributed projects. For that, it was evaluated whether they have or not the managerial and collaborative functionalities that we outlined as ideal to handle distributed projects.

In this paper we review some of the problems associated with traditional project management and we explain why collaborative project management is the adequate approach to deal with distributed projects. We also bring up the concept of project management software and collaboration. This paper also proposes a framework of functionalities that a collaborative project management software should have to deal with distributed projects. In the end, a survey was carried out, to see if some software packages are suitable or not to handle efficiently distributed projects. These software packages will be also classified according to the collaboration level that they support.

\subsection{Collaborative Project Management}

Over the past two decades, the economic globalization and market dynamics have been increasing the need for business partnerships and projects across nations [4]. Thanks to the information technology advances, projects with collaborators from different geographical locations, organizations and cultural backgrounds became in large number effectively implemented $[5,6]$. Issues like negotiation of the project goals, scheduling, task allocation, parallel working on the same task and resource sharing requires particularly high degrees of collaboration among distributed team members [2]. As collaboration has become an important part of project management, the traditional project management paradigm has been shifting toward a more Collaborative Project Management (CollabPM) paradigm [4]. The traditional project management approach focuses on a single project at a single location and some of its common mistakes include: ineffective information flow and communication between all the team members, distant project tracking, a reactive management approach and lacks of a document management system. Together all these mistakes account for the reason why many distributed projects either fail or are significantly less efficient than they could be [2-4]. The collaborative project management model is more concerned with efficient sharing of information in all directions, better communication among project contributors, close tracking of the project work, proactive management and the presence of a document management system. These are some of the important issues required to successfully implement distributed projects [6, 7]. The CollabPM paradigm has emerged as a vehicle by which the cost and duration of distributed projects can be potentially reduced while maintaining the quality and scope of the projects [3]. 


\subsection{Project Management Software}

The project management paradigm has changed not only in terms of how projects are managed but also in terms of computing environments. In the past, project management meant three things: pencil, paper and brains. However, over the last decades, the arising of personal computers (PC) and the growth of project management software (PMS) has especially contributed to change the face of project management $[3,8]$. Nowadays, it is almost unthinkable that anyone would plan and manage a project without the support of PMS. Managing a project involves a considerable data and information analysis that cannot be easily handled without the aid of PMS. Even for simple projects developed at a single location, making changes and updating the entire network is something difficult to do without using a PMS [9]. Moreover, unlike local projects, in globally dispersed projects, face-to-face interactions among project contributors are often impossible. Thus, as the number of distributed projects increases and the project management shifts towards a CollabPM paradigm, information and communication technology solutions are needed for converting physical collaborative actions into virtual ones [2]. As organizations deal with projects with distributed teams, the management, communication, coordination and tracking of ongoing project work must rely on a specific kind of PMS, called Collaborative Project Management Software (CollabPMS) [7]. The CollabPMS helps people to manage projects and collaborate more easily regardless of their geographical location, in more efficient and effective ways than ever before to successfully achieve the project's goal $[4,10]$. Although many companies claim they have CollabPMS packages, they are not all equal. Depending on the type of computer applications that they have, these CollabPMS can support different levels of collaboration. As people collaborate, there are at least two hierarchic levels in which they can work to achieve the project's purpose, namely coordinated level and concerted level [11] (Figure 1).

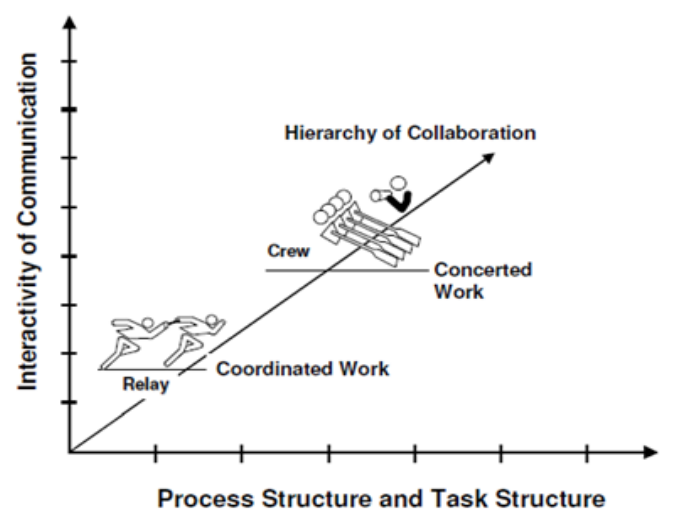

Fig. 1. The hierarchy of collaboration, adapted from [11] 
Coordinated Level - In this collaboration level, team members make individual performances and the success of each team member depends on the timely receipt of deliverables from other members. Therefore, team productivity depends on the ability to coordinate efforts and is the sum of the sequential individual performances. Regarding the task structure, the project tasks follow a sequential order and there is a progressive integration of the work. Because, in this level, the coordination among project team members is required, there is a great need of interactive communication. Typical computer applications to support coordinated work include electronic mail, workflow automation and group calendaring [11].

Concerted Level - Represents a higher level of collaboration. At this level, the performance of any member may directly and immediately influence the performance of all members. Thus, the concerted level requires tight coordination among project individuals and the team productivity is the sum of all concerted team performances. Task structure is more demanding for concerted work than for coordinated work because results need to be continuously integrated and any behavior of each team member directly affects the work of others. Furthermore, at this stage of collaboration, the need for interactive communication is nearly continuous. A typical computer application to support concerted work is called Group Support System (GSS) [11].

\section{Analysis of Project Management Software Packages}

A number of project management architectures have been proposed, as Dixon's (1988) model which only involves planning and scheduling the activities, resource identification and allocation and cost management. Dixon's model does not include document management system and hasn't also any collaborative aspect. Therefore it underestimates the complexity of distributed projects and the collaboration required to make them successful. Maurer (1996) presents a generic architecture that allows users analyze dependencies between information items and plan the project in terms of time and resources. The Maurer's model also supports workflow management and project monitoring. This model does allude to collaboration; however it focuses only on the coordination level, and does not address the concerted level [4].

Our research goal is to outline which important functionalities a CollabPMS should provide to support the complexities of a distributed project effectively. Therefore, the following sections will describe the managerial functionalities that a CollabPMS should have to support an efficient management of distributed projects. Additionally, because projects with team distribution requires high degrees of collaboration among them, to successfully achieve the project's goal, this research also describes which collaborative functionalities a CollabPMS should have to support the different levels of collaboration. Currently, the market is loaded with hundreds of software packages to assist in project management. From the current generation, four software packages were selected, namely, ProjectLibre, Redmine, MPP 2013 and Clarizen to assess whether they have or not the managerial and collaborative functionalities that we outlined as ideal to handle distributed projects. 


\subsection{Managerial Functionalities}

An ideal CollabPMS should provide a set of managerial functionalities capable of answering to the challenges placed by the project team and providing, at the same time, an integration of all the project's processes over its life cycle [12]. Based on the work developed by Jaafari and Manivong (1998), we describe a series of managerial functions (table 1, first column) that a CollabPMS should offer to help perform an efficient management of distributed projects. Using a project example adapted from Hillier and Lieberman (2010) about constructing a new plant for a major manufacturer was possible to evaluate whether ProjectLibre has $(\checkmark)$ or hasn't $(\mathbf{x})$ the managerial functionalities outlined to perform efficient project management. Moreover, based on published information, that is, scientific papers and information sourced from the software companies' websites, it was possible to perform the same evaluation on Redmine, Microsoft Project Professional 2013 (MPP 2013) and Clarizen. The results of these evaluations can also be found in Table 1.

Table 1. Managerial functionalities matrix

\begin{tabular}{|c|c|c|c|c|}
\hline Software Name & ProjectLibre & Redmine & MPP 2013 & Clarizen \\
\hline Type of software & Desktop & Web-based & Desktop & Web-based \\
\hline License & Open source & Open source & Proprietary & Proprietary \\
\hline Company & ProjectLibre & Redmine & Microsoft & Clarizen \\
\hline Price & Free & Free & $\begin{array}{c}\$ 1,159 \text { per } \\
\text { PC }\end{array}$ & $\begin{array}{c}\$ 29,95 \\
\text { /user/month }\end{array}$ \\
\hline Trial version & - & - & $\checkmark$ & $\checkmark$ \\
\hline Gantt Chart & $\checkmark$ & $\checkmark$ & $\checkmark$ & 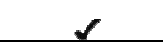 \\
\hline Task dependencies & $\alpha$ & $\alpha$ & 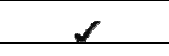 & $\Omega$ \\
\hline Critical path & $\alpha$ & $x$ & $\checkmark$ & $\checkmark$ \\
\hline Milestones & $\alpha$ & $\mathbf{x}^{1}$ & $\checkmark$ & 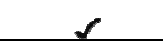 \\
\hline Resources Allocation & $\checkmark$ & $\mathbf{x}^{1}$ & $\checkmark$ & $\checkmark$ \\
\hline Budgeting & $\alpha$ & $x^{1}$ & $\checkmark$ & 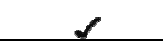 \\
\hline Simulation & 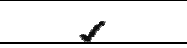 & $\Omega^{2}$ & $\gamma$ & $\checkmark$ \\
\hline Setting Baseline & $\checkmark$ & $\checkmark$ & $\checkmark$ & $\checkmark$ \\
\hline Project tracking & 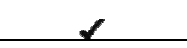 & $\alpha$ & $\alpha$ & 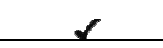 \\
\hline Portfolio Management & $x$ & $\alpha$ & $x^{3}$ & $\checkmark$ \\
\hline Reporting & $\checkmark$ & $\Omega^{4}$ & $\checkmark$ & $\checkmark$ \\
\hline Document Management & $x$ & $\mathcal{L}$ & $x^{5}$ & $\mathscr{r}$ \\
\hline $\begin{array}{l}\text { Importing and Exporting } \\
\text { data }\end{array}$ & XML & XML & $\begin{array}{l}\text { XML, CSV, } \\
\text { TSV }\end{array}$ & XML \\
\hline
\end{tabular}

\footnotetext{
${ }^{1}$ There is the option of setup a free plugin.

${ }^{2}$ Only scheduling simulations.

${ }^{3}$ There is the option of setup Project Server 2013 (sold separately).

${ }^{4}$ Reporting only regarding work in progress.

${ }^{5}$ There is the option of setup SharePoint 2013 (sold separately).
} 
Project scheduling plays a crucial role in ensuring the success of a project [9]. Analyzing Table 1, it is possible to verify that all the software packages, provide the functionality Gantt chart and task dependencies [13-15]. Furthermore, ProjectLibre, MPP 2013 and Clarizen allow to calculate and highlight the critical path in the Gantt chart, while Redmine does not calculate neither displays the critical path $[16,17]$. Milestones are useful for the project manager to evaluate if the schedule itself is proceeding as expected [9]. ProjectLibre, MPP 2013 and Clarizen let establish milestones along the project's schedule $[18,19]$. The Redmine program does not have this feature. Yet, this issue can be solved by installing a free plugin from the Redmine plugins directory which adds milestones [20]. For the planning phase to be completed, after scheduling the project's activities, it is necessary to deal with resources and costs planning [9]. ProjectLibre, MPP 2013 and Clarizen allow to carry out the allocation of resources $[21,22]$. Redmine does not allow resource allocation, however, once again, this problem can be overcome by installing a free plugin for assigning resources [23]. ProjectLibre, MPP 2013 and Clarizen allow to calculate the cost of each resource and, in the end, establish a budget for the project $[21,24]$. By installing a costless plugin for budgeting, Redmine is also able of manage costs [25]. In relation to the simulation or what-if scenarios, like ProjectLibre, both MPP 2013 and Clarizen allow the project manager to go into schedule, resources and cost simulations to find the best answer to the project constraints. For Redmine to be able to simulate trade-offs like resources versus time, or costs versus time, the project manager has to install the plugins for budget and resources allocation, otherwise with Redmine it is possible only to make simulations on the project schedule. Regarding the baseline functionality all the software packages offer the option of saving the baseline plan [26-28]. All the software packages also afford tracking the project progress [21, 28, 29]. Both Clarizen and Redmine offer the Portfolio Management functionality, but like ProjectLibre, the MPP 2013 does not provide the management of a portfolio. However, it is possible to unlock this functionality by installing the Microsoft Project Server 2013, which is sold separately from MPP 2013 and is a flexible program for project portfolio management [30]. In reference to the reporting functionality, ProjectLibre, MPP 2013 and Clarizen offer a set of predefined reports to see the overall project's status. These reports can provide information related to work in progress, resources and budget. Redmine also provides a predefined report, but this report only provides information on the work in progress $[21,31]$. The functionality of document management system is displayed for Clarizen and Redmine [21, 28]. ProjectLibre does not provide a document management system, like MPP 2013. The SharePoint 2013 is a paid web application platform developed by Microsoft Corporation that can interface with MPP 2013 and includes document management [32]. ProjectLibre, Redmine and Clarizen can interface with the different versions of MPP because both allow to export and import entire projects in the XML format. Additionally, to create XML files, MPP 2013 allows to import and export data in comma-separated values (CSV) file format and Tab Separated Values (TSV) file format [28, 33]. 


\subsection{Collaborative Functionalities}

Particularly for projects which have their team members spread in different places and tasks depending on different team members' performance, the collaboration between the members is crucial [34]. We used the work developed by Nunamaker et al. (2002) about the typical computer applications that are required to support the coordinative and concerted levels of collaboration, to define which collaborative functionalities a CollabPMS should provide to efficiently support the distributed teams. We define like them that and ideal CollabPMS must be designed to provide the concerted level of collaboration. It is the concerted level of collaboration that adds real value to project management, therefore an ideal CollabPMS must afford the GSS technology (see section 1.2) [4]. Moreover we use their work to classify the software packages ProjectLibre, Redmine, MPP 2013 and Clarizen according to the collaboration level that they support. Therefore, was necessary to evaluate whether these four software packages have $(\checkmark)$ or do not have $(\boldsymbol{x})$ the typical collaborative functionalities that are required to support each of the two collaboration levels. Table 2 displays the results of this evaluation.

Table 2. Matrix of collaborative functionalities

\begin{tabular}{|c|c|c|c|c|}
\hline Software Name & ProjectLibre & Redmine & MPP 2013 & Clarizen \\
\hline Type of software & Desktop & Web-based & Desktop & Web-based \\
\hline License & Open source & Open source & Proprietary & Proprietary \\
\hline Company & ProjectLibre & Redmine & Microsoft & Clarizen \\
\hline Price & Free & Free & $\begin{array}{c}\$ 1,159 \text { per } \\
\text { PC }\end{array}$ & $\begin{array}{c}\$ 29,95 \\
\text { /user/month }\end{array}$ \\
\hline Trial version & - & - & $\mathscr{L}$ & $\alpha$ \\
\hline Email & $x$ & $\checkmark$ & $x^{6}$ & $\checkmark$ \\
\hline Workflow Automation & $x$ & $\checkmark$ & $\mathbf{x}^{7}$ & $\checkmark$ \\
\hline Group calendaring & $x$ & $\gamma$ & $x^{7}$ & $\gamma$ \\
\hline GSS & $x$ & $x$ & $x$ & $x$ \\
\hline
\end{tabular}

Clarizen offers its clients several collaborative functionalities as email, workflow automation and group calendar [21, 35]. Nevertheless, Clarizen has not adopted the GSS technology. The MPP 2013, commercialized by Microsoft Corporation, does not provide by default the email and the workflow functionality. But, by setting up Microsoft Lync 2013, emails between team members can be exchanged [36]. Moreover, by installing Microsoft SharePoint, it is possible to have workflow automation [37]. Regarding group calendar, MPP 2013 does not have this capability; however, by setting up SharePoint, this drawback can be solved [38]. It is important to keep in mind that both Lync and SharePoint are sold separately from MPP 2013. Like Clarizen, MPP 2013 does not include GSS. Redmine provides email, workflow

\footnotetext{
${ }^{6}$ There is the option of setup Lync 2013 (sold separately).

${ }^{7}$ There is the option of setup SharePoint (sold separately).
} 
and group calendar functionalities but does not provide the GSS [28]. ProjectLibre does not have any collaborative functionality to support any of the two levels of collaboration.

\section{Discussion}

Our architecture considers more factors or functions (table 1 and 2) than the previous two models. This architecture allows establish interdependency of tasks, forming the project team, assigning resources and tasks to team members, defining milestones for the project, making project schedule, project tracking, document management system, reporting, portfolio management, import and export data. Only a software architecture with all this managerial functions is able to effectively supporte distributed teams [12]. Moreover, only a collaborative platform that allows the concerted level of collaboration can facilitate group discussion and negotiation [4].

The review of table 1 shows that Clarizen is the only software offering by default, all the managerial functionalities that ideal software should have to support an efficient project management. The MPP 2013, commercialized by Microsoft Corporation, is also able to provide the same overall managerial functionalities. However, for that, their clients must pay for complementary programs (see section 2.1). Redmine does not provide one of the essential managerial functionalities, the critical path analysis function. Capabilities like milestones, resource allocation and budgeting, which are not also provided by default, can be installed as plugins by the users for free. ProjectLibre like Redmine is an open source software with free license, but in ProjectLibre lacks two functionalities, namely, the Portfolio management and document management system (table 1). Although the four PMS packages range between open source and proprietary, desktop and web-based application, all the selected PMS somehow cover the traditional management areas, that is, scheduling, resource allocation, costs and project control, areas that are essential for project management [3, 12]. It should be noticed that Redmine was included in this observation because it offers free plugins that allow specifically to manage these traditional areas. Considering the price of each PMS, there are two distinct groups: group 1- ProjectLibre and Redmine with free licensing and group 2 - MPP 2013 and Clarizen with paid licensing. It is possible to verify that the companies of group 2 , Clarizen Incorporated and Microsoft Corporation are able to provide their clients with respectively a PMS or a combined PMS solution which frames into the concept of what is an ideal PMS to manage projects efficiently [12]. The study of Liberatore \& Pollack-Johnson (2003) contributes somehow to this observation. According to them, high-end packages, that is, those PMS packages that are more expensive, tend to have more features capable of handling with huge and complex projects than the less expensive ones. They also state that larger firms are those that can usually afford more expensive PMS [39]. The concerted level of collaboration truly offers effective and efficient support for managing the complexities of a distributed project [4]. At this level, all the team members must contribute in concert to the group efforts. Therefore, the performance of any team member influences the other members' 
performance [4, 7]. Group Support System (GSS) is the commonly used technology to support the concerted level of collaboration [11]. The GSS can be defined as an information technology specifically designed to provide structured process support for group meetings. The GSS technology allows team members collaborate and increases the effectiveness of decision making while reducing travel expenses [40]. However, none of the four software packages already discussed have invested in GSS technology, as a consequence they don't support group problem solving and decision making [3, 6]. Therefore, none of the software packages support concerted work. The Redmine and Clarizen are both web-based software packages and have all by default the functionalities to address the coordinated level of collaboration; explicitly they have email, workflow automation and group calendar capabilities. In the coordinated level, the team success depends on the ability to coordinate efforts [3]. While Redmine offers all the capabilities of the coordinated work for free, in Clarizen it is required to pay, that is, it is needed to purchase the software. The MPP 2013, plus its third party applications as SharePoint and Lync 2013, can also provide coordinated work to its users. But, for that the costumer must be willing to pay for the MPP 2013 and an extra for web-based third party applications. Moreover ProjectLibre doesn't support any of the two collaboration levels, it doesn't present any collaborative feature therefore can be considered inadequate for managing distributed projects [3]. It is possible to notice that collaboration in distributed projects needs a web-based infrastructure; this observation supports the finds of Chen et al. (2006) that software packages with web interface are the ones that can fully support collaboration among dispersed team members. The author Romano et al. (2002) developed a study about collaborative project management software and his conclusions were that most of the CollabPMS available at that time in the market just provided the lower levels of collaboration. For example, the Microsoft Project 2000 which was one of the selected software packages by Romano provided at that time coordinated work [7]. Nowadays, the version of Microsoft Project 2013 (MPP 2013) still provides the coordinated level. In the past, researchers had been proposing and developing CollabPMS prototypes to support concerted level [4, 7]. At the present, there is still the need to improve the software packages to provide concerted collaboration to companies who need it.

\section{Conclusions}

None of the four tested software packages have all the functionalities that we describe as ideal to support the implementation of distributed projects, because none of them provides the GSS functionality, and therefore they are not able to afford the concerted level of collaboration. As a result it is needed that these software packages and possibly the entire PMS market moves forward to provide a continuous collaboration among distributed team members. Nevertheless, in the overall scenario Clarizen can be considered the best software for managing distributed projects because it is the only one that, by default, provides all the outlined managerial functions and all the collaborative features that support the coordinated collaboration level. ProjectLibre was the software that performed the worst in this evaluation because of lack of 
support for any level of collaboration despite providing the majority of the outlined managerial functionalities.

\section{References}

1. Project Management Institute: A Guide to the Project Management Body of Knowledge. Project Management Institute (2008)

2. Evaristo, R., van Fenema, P.C.: A typology of project management: emergence and evolution of new forms. Int. J. Proj. Manag. 17, 275-281 (1999)

3. Chen, F., Romano, N.C., Nunamaker, J.F.: A Collaborative Project Management Approach and a Framework for its Supporting Systems. J. Int. Technol. Inf. Manag. 15, 1-16 (2006)

4. Chen, F., Nunamaker, J.F., Romano, N.C.: A Collaborative Project Management Architecture. In: Proceedings of the 36th Hawaii International Conference on System Sciences (2002)

5. Helbrough, B.: Computer assisted collaboration - the fourth dimension of project management? Int. J. Proj. Manag. 13, 329-333 (1995)

6. Nunamaker, J.F., Romano, N.C., Briggs, R.O.: A framework for collaboration and knowledge management. In: Proceedings of the 34th Annual Hawaii International Conference on System Sciences (2001)

7. Romano, N.C., Fang, C., Nunamaker, J.F.: Collaborative Project Management Software. In: Proceedings of the 35th Hawaii International Conference on System Sciences (2002)

8. Reiss, G.: Project Management Demystified: Today's Tools and Techniques. Spon Press (1995)

9. Marchewka, J.T.: Information Technology Project Management: Providing Measurable Organizational Value. Wiley Publishing (2003)

10. Nidiffer, K.E., Dolan, D.: Evolving Distributed Project Management. IEEE Softw. 22, 63-72 (2005)

11. Nunamaker, J.F., Romano, N.C., Briggs, R.O.: Increasing Intellectual Bandwidth: Generating Value from Intellectual Capital with Information Technology. Gr. Decis. Negot. 11, 69-86 (2002)

12. Jaafari, A., Manivong, K.: Towards a Smart Project Management Information System. Int. J. Proj. Manag. 16, 249-265 (1998)

13. Microsoft Corporation: Choose the right view of your project schedule, http://office.microsoft.com/en-us/project-help/ choose-the-right-view-of-your-project-scheduleHA102749464 . aspx?CTT=5\&origin=HA102926132

14. Clarizen Incorporated: Clarizen Releases Version 2.5G with Time Tracking and Gantt Chart, http://www.clarizen.com/media-center/press-releases/ clarizen-partners-with-mulesoft-to-accelerate-customertime-to-value-with-automated-applicationintegrations/item/clarizen-releases-version2-5g-with-time-tracking-and-gantt-chart.html

15. Redmine: Gantt Chart, http: / /www . redmine.org/issues / 14582

16. Microsoft Corporation: Show the critical path of your project, http://office.microsoft.com/en-us/project-help/ show-the-critical-path-of-your-project-HA102748968.aspx 
17. Clarizen Incorporated: How To View the Critical Path, https: //success.clarizen.com/entries/ 24078911-v5-How-To-View-the-Critical-Path

18. Microsoft Corporation: Add a milestone, http://office.microsoft.com/ en-us/project-help/add-a-milestone-HA102748898.aspx

19. Clarizen Incorporated: What is a Milestone, https: / / success.clarizen.com/entries/ 24128683-What-is-a-Milestone-

20. Redmine: Plugins Directory - Milestones, http://www.redmine.org/plugins/redmine_milestones

21. Clarizen Incorporated: Features A - Z, http://www.clarizen.com/projectmanagement-solutions/online-project-management-features.html

22. Microsoft Corporation: How do resource assignments drive the schedule?, http: / / office.microsoft.com/en-us/project-help/ how-project-schedules-tasks-behind-the-scenesHA102749287.aspx?CTT=1\#_Toc312058394

23. Redmine: Plugins Directory - Allocation, http: / / www.redmine.org/plugins/redmine_allocation

24. Microsoft Corporation: Enter rate-based costs for people and materials, http: //office.microsoft.com/en-us/project-help/enter-ratebased-costs-for-people-and-materials-HA103465589. aspx?CTT=1

25. Redmine: Budget Plugin, http: / /www.redmine.org/projects/redmine/ wiki/pluginbudget

26. Microsoft Corporation: Set and save a baseline, http: / / office.microsoft.com/ en-us/project-help/set-and-save-a-baseline-HA102809638.aspx

27. Clarizen Incorporated: Save as Baseline, https : / / success . clarizen.com/ entries/24092307-v5-Save-as-Baseline

28. Redmine: Redmine Features, http: / /www. redmine.org/

29. Microsoft Corporation: Project Professional (2013), http://office.microsoft.com/en-us/project/ professional-project-management-desktop-softwareproject-professional-FX103797571.aspx

30. Microsoft Corporation: Choose your Project, http://office.microsoft.com/en-us/project/ project-management-and-ppm-software-comparisonsmicrosoft-project-FX103797367.aspx

31. Microsoft Corporation: Pick the right report, http: //office.microsoft.com/en-us/project-help/ pick-the-right-report-HA102843515. aspx?CTT=1

32. Microsoft Corporation: Plan document management in SharePoint (2013), http: / / technet.microsoft.com/en-us/library/cc263266.aspx

33. Clarizen Incorporated: Can I export my work plan?, https://success.clarizen.com/entries/ 24127676-Clarizen-Community-FAQ

34. Evaristo, J.R., Munkvold, B.E.: Collaborative infrastructure formation in virtual projects. J. Glob. Inf. Technol. Manag. 5, 29-47 (2002)

35. Clarizen Incorporated: Clarizen: Creating Workflow Solutions to Transcend Generations, http: / / technorati.com/business/article/ clarizen-creating-workflow-solutions-to-transcend 
36. Microsoft Corporation: Using Lync, http://office.microsoft.com/ en-us/sharepoint-server-help/use-a-group-calendarHA101810606. aspx?CTT=1

37. Microsoft Corporation: Introduction to workflows, http: //office.microsoft.com/en-us/sharepoint-serverhelp/introduction-to-workflows-HA010154424.aspx

38. Microsoft Corporation: Use a Group Calendar, http://office.microsoft.com/en-us/ sharepoint-server-help/use-a-group-calendarHA101810606. aspx?CTT=1

39. Liberatore, M.J., Pollack-Johnson, B.: Factors influencing the usage and selection of project management software. IEEE Trans. Eng. Manag. 50, 164-174 (2003)

40. Hayen, R.L., Swaby, S.A., Huang, Z.: Use of Group Support Systems in Today's Society. Issues Inf. Syst. 7, 120-126 (2007) 